\title{
Advances in Limb Lengthening and Reconstruction
}

\author{
Alessandro Codivilla, MD, 1861-1912
}

\author{
Richard A. Brand MD
}

Published online: 18 September 2008

(C) The Association of Bone and Joint Surgeons 2008

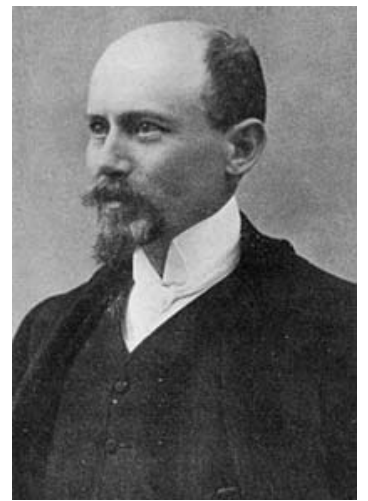

Dr. Alessandro Codivilla is shown. Figure provided by and reprinted with kind permission of Dr. Anna Viganò, Director of the Umberto I Library, and Mrs. Patrizia Tomba.

Alessandro Codivilla was born and raised in Bologna. His father was a pawnbroker [4] and he evidently tutored students to finance his education. He completed his medical education at the University of Bologna in 1886 and trained in general surgery as an assistant to Loreta and Poggi, following which he had successive appointments at several hospitals. In 1898 he was offered the directorship of the Rizzoli Institute of Bologna, which he accepted as of January, 1899, and at which time he elected to exclusively practice orthopaedics [6]. However, prior to beginning his appointment, he traveled to a number of centers in Europe to gather experience. The Rizzoli had been founded by the Bolognese surgeon, Francesco Rizzoli, who purchased a convent and the hill of San Michele in Bosco [6], just south

R. A. Brand $(\square)$

Clinical Orthopaedics and Related Research, 1600 Spruce Street, Philadelphia, PA 19103, USA

e-mail: dick.brand@clinorthop.org

of Bologna (and where still stands the Church of San Michele constructed by Olivetan monks between 1517 and 1523). Rizzoli left the property in his will to the Province of Bologna to be used as an orthopaedic hospital. The Institute opened in 1896 and quickly became prominent in the world of orthopaedic surgery in large part owing to the work of Codivilla and then Vittorio Putti, who succeeded Codivilla in 1912 upon Codivilla's death [9]. (Putti, an inveterate scholar, amassed one of the world's largest collections of historic books related to surgery and orthopaedics, and that collection now contains more than 32,000 volumes [6].)

Codivilla, a quiet and apparently humble man of nonetheless great energy, reported new ways to treat many conditions, including polio residuals, clubfoot, scoliosis, and congenital dislocation of the hip. He published 124 articles, collected in two volumes by Bartolo Nigrisoli and printed in 1944; of those 25 were in foreign languages and published in the periodicals of their respective countries [6]. There was some controversy about the priority of the use of pins for skeletal traction [5]. Codivilla's 1903 report [1] described the use of skeletal traction for treating malunions, while Steinmann's later reports [7, 8] in 1907 and 1910 advocated its use in the treatment of fresh fractures.

There appears no controversy regarding Codivilla's report of external pin fixation and traction for limb lengthening $[1,2]$. We republish here his first publication in English, from 1905 (which was presented at the Annual Meeting of the American Orthopaedic Association in June, 1904), two years after his initial description in Italian. Codivilla acknowledged, however, he was not the first to try limb lengthening:

"In consulting works on the subject, we find that surgeons have adopted very diverse courses in cases 
of lengthening the fleshy parts, where there is shortening of the limbs. The greater number have applied constant traction, after having separated the bone; others have used great stretching, under narcotics, followed by constant extension of the muscles, by means of weights; others again, after the stretching, have applied the plaster apparatus. A very notable difference exists also as regards the degree of force which has been applied with the weights, ranging from a small, to a high number of kilogrammes, without a proportionate difference existing in the condition of the resistance of the muscles, in relative cases" [2].

He recognized the largely empirical nature of the surgeon's choices, and commented, "It is now time that we should earnestly endeavor to free ourselves from blind and empiric custom, and discover the means of lengthening the tissues to their greatest possible extent, while compatible with the maintenance of their physiologic functions" [2]. He believed for relatively small degrees of shortening the best approach involved acute "forced lengthening, practiced under narcotics..." But for larger degrees, "...it would be dangerous..." [2]. He advocated moderate traction ( $\sim 25$ kilograms) applied through a pin ("nail") in the calcaneus and using ferrule attached to a plaster (Figs. 910 in the reproduced article) to incrementally apply traction after an interval of a few days either without or with narcotics as appropriate. He noted the desired lengthening could be obtained in an average of 20 days, although the procedure could continue for 30-35 days without a major problem with the pin. He mentioned the use of this approach in 26 patients, including 11 with old fractures of the femur, one with coxa vara, five with various causes of shortening (e.g., growth plate stoppages, dislocations), three fractures of the leg, one pseudarthrosis of the upper third of the leg, and two fractures of the ankle with "serious lateral deviations." "The method," Codivilla concluded, "has borne the very best results, correcting the deformity, and diminishing, or completely removing the shortness of the limb" [2]. More recent refinements, notably those of Ilizarov [3], used multiple pins applied through external frames, and with specified programs for lengthening. The concepts, however, arise from Codivilla's initial report.

\section{References}

1. Codivilla A. Sulla correzione della deformita de frattura del femore. Bull Sci Med (Bologna). 1903;3:246-249.

2. Codivilla A. On the means of lengthening, in the lower limbs, the muscles and tissues which are shortened through deformity. $J$ Bone Joint Surg Am. 1905;s2-2:353-369.

3. Ilizarov GA, Deviatov AA. Surgical lengthening of the shin with simultaneous correction of deformities [in Russian]. Ortop Travmatol Protez. 1969;30:32-37.

4. Mostofi SB, ed. Who's Who in Orthopedics. Heidelberg, Germany: Springer-Verlag; 2004.

5. Peltier L. The role of Alessandro Codivilla in the development of skeletal traction. J Bone Joint Surg Am. 1969;51:1433.

6. Servizio Sanitario Regionale Emiglia-Romagna - Istituto Ortopedico Rizzoli di Bologna. 2008. Available at: http://www.ior.it/. Accessed August 18, 2008.

7. Steinmann F. Eine neue Extensionsmethode in der Frakturenbehandlung. Zentralbl Chir. 1907;34:153-156.

8. Steinmann F. Zur Autoschaft der Nagelextension. Zentralbl Chir. 1910;37:153-156.

9. Vittorio Putti. J Bone Joint Surg Am. 1941;23:187-189. 